\title{
EL LENGUAJE DISCRIMINATORIO EN LA ANTIGUA ROMA Y EN LA ESPAÑA ACTUAL
}

\author{
María José Bravo Bosch \\ Doctora en derecho romano. Profesora Titular de Derecho \\ Romano en la Universidad de Vigo y de Sistemas \\ Jurídicos Contemporáneos: Derecho Continental y \\ derecho anglosajón. Visiting professor en las \\ Universidades de Messina y Cagliari (Italia), con estancias \\ de investigación en: Florencia, Munich (Leopold Wenger \\ Institut), Foggia, Göttingen. \\ bravobosch@gmail.com
}

RESUMEN: En este trabajo analizamos con detalle el lenguaje discriminatorio contra la mujer en el mundo romano. Adjetivos despectivos relativos a la incapacidad femenina y a la debilidad de su espíritu nos dejan clara la posición de la mujer en la antigua Roma, sometida a tutela perpetua con un hombre como tutor que debe prestar su auctoritas para determinados actos jurídicos, en un espacio dominado por la sociedad patriarcal. A continuación, hacemos un breve recorrido por la España actual para poner de manifiesto la necesidad de seguir luchando por la efectiva paridad por medio de un lenguaje inclusivo claro y coherente que permita la consecución de la tan ansiada igualdad

PALABRAS CLAVE: Mujer. Infirmitas sexus. Tutela mulierum. Lenguaje inclusivo.

\section{Linguagem discriminatória na Roma Antiga e na atual Espanha}

RESUMO: Neste artigo analisamos detalhadamente a linguagem discriminatória contra as mulheres no mundo romano. Adjetivos desalentadores em relação à incapacidade feminina e a fraqueza de seu espírito tornam clara a posição das mulheres na Roma antiga, sujeitas à tutela perpétua com um homem como guardião que deve emprestar seus auctoritas para certos atos legais, em um espaço dominado pela sociedade patriarcal. A seguir, fazemos um breve passeio pela atual Espanha para destacar a necessidade de continuar lutando por uma paridade efetiva através de uma linguagem clara e coerente e inclusiva que permita alcançar a tão desejada igualdade.

PALAVRAS-CHAVE: Mulher. Infirmitas sexus. Tutela mulierum. Linguagem inclusiva.

\section{Discriminatory language in ancient Rome and current Spain}

ABSTRACT: In this paper we analyze in detail the discriminatory language against women in the Roman world. Disparaging adjectives relating to female incapacity and the weakness of her spirit make clear the position of women in ancient Rome, subject to perpetual tutelage with a man as guardian who must lend his auctoritas for certain legal acts, in a space dominated by the patriarchal society. Next, we make a brief tour of the current Spain to highlight the need to continue fighting for effective parity through a clear and coherent inclusive language that allows the achievement of the much desired equality.

KEYWORDS: Woman. Infirmitas sexus. Tutela mulierum. Inclusive language. 


\section{INTRODUCCIÓN}

Nuestro propósito es demostrar como el lenguaje puede incidir de una manera decisiva a la hora de acreditar o desacreditar un género, en este caso el femenino. Partiendo del concepto decididamente discriminatorio en la antigua Roma, y de la exégesis de los textos más controvertidos con respecto a la mujer en el derecho romano, haremos una comparación seguramente excesiva por el salto temporal, pero necesaria, para ver cuánto hemos cambiado, en qué hemos avanzado y en dónde retrocedido, con la intención última de demostrar la necesidad de un lenguaje inclusivo que ponga en situación de paridad, en cualquier momento, en cualquier lugar y en todo caso, a la mujer con respecto al hombre.

El problema de la igualdad y los derechos que conlleva son objeto hoy en día de un amplio debate. La respuesta activa con respecto a los conflictos de género merece una respuesta adecuada, y mucho más si tenemos en cuenta la misoginia secular presente en el lenguaje diario. Este pensamiento patriarcal no significa que las mujeres fueran denostadas en todo momento, o que no estuvieran presentes en la mente de juristas y legisladores a la hora de elaborar corpus doctrinales o conjuntos de normas determinados, porque no sería cierto. La inclusión femenina en la regulación jurídica tenía por objeto a las mujeres, pero con reglas minuciosas y precisas dirigidas a la tutela y la subordinación femenina. Es decir, "tengamos en cuenta a las mujeres para poder someterlas adecuadamente, dentro de unos límites que no puedan sobrepasar", en aras de la eterna permanencia del sistema patriarcal.

Con todo, la historiografía demuestra los avances en el ámbito del género y la paridad, y la antaño habitual exclusión de las mujeres se ha convertido en una lucha diaria en pro de la igualdad. Pero no se trata de una contienda teórica, que se traduzca en una mejora ostensible de los derechos femeninos en las leyes, reglamentos y demás disposiciones normativas que les puedan afectar, sino de la necesidad de traducir en la práctica de la vida cotidiana esa igualdad de sexos.

El derecho romano, precisamente, se distinguió desde sus orígenes por la visibilización de las mujeres en las fuentes de producción y conocimiento del ius, pero no nos llevemos a engaño, con la intención netamente masculina y propia del pensamiento de un paterfamilias, de someter a estricta vigilancia cualquier exceso femenino que pudiera perjudicar al conjunto de la gens familiar. La discriminación de las mujeres y la minusvaloración permanente consiguió el objetivo perseguido: crear en la conciencia de los ciudadanos romanos la idea de que las mujeres debían ser tuteladas de por vida, por su fragilidad de ánimo, y como veremos a continuación, por su débil condición.

Los juristas romanos, por lo tanto, debían realizar una construcción jurídica de los términos adecuados para referirse a las mujeres, y con el tiempo fueron utilizando la gran mayoría los mismos epítetos, todos ellos peyorativos.

\section{SEXo DÉBIL}

El término utilizado con más frecuencia para referirse a la debilidad de las mujeres fue 'infirmitas'. Esta fragilidad implica todos los aspectos de la condición femenina, y resulta equivalente a una suerte de incapacidad, sin ningún valor autónomo como el perteneciente a la

\footnotetext{
1 A. BERGER, Encyclopedic Dictionary of Roman Law, Filadelfia 1953, reimp. 1991, s.v. infirmitas aetatis (or sexus): "The weakness of an individual because of his age (or sex). It is given as a reason for guardianship or curatorship over a persona under a certain age or over women".
} 
virilidad, es decir, lo femenino sería el elemento negativo, y la convicción moral de la sociedad romana aceptaría de buen grado esta singular acepción.

Uno de los primeros en utilizar estos términos fue el famoso Cicerón, que utiliza el calificativo de infirmitas en relación con la debilidad de las mujeres, en Pro Murena 12. 27²:

Mulieres omnis propter infirmitatem consilii maiores in tutorum potestate esse voluerunt.

Es cierto que no encontramos todavía la unión del término infirmitas con sexus, pero del mismo modo Cicerón relaciona la debilidad de juicio con la condición femenina, lo que viene a significar exactamente lo mismo. Con todo, hay que decir que Cicerón no nos ofrece su consideración al respecto, no podemos tildar su intervención de discriminatoria ya que lo único que hace es recordar la decisión de los antepasados con respecto al colectivo femenino, sin rendir un juicio positivo con respecto a esa tutela perpetua obligatoria para las mujeres, pero el recordatorio desde luego no ayuda a la liberación de la tutela por parte de la mujer, aunque el célebre jurista pronunciase dichas palabras en una época cercana a la supresión parcial de la tutela mulierum por parte del emperador Augusto, aunque fuera con el objetivo de incrementar la natalidad con la concesión del ius liberorum.

\subsection{Tutela mulierum}

Debemos recordar como en la antigua Roma las mujeres sui iuris ${ }^{3}$, es decir, las que por su status familiae no deberían estar sometidas a la autoridad de otra persona, se encontraban sujetas a una tutela perpetua debido a su condición ${ }^{4}$, la tutela mulierum ${ }^{5}$, mediante la cual, al terminar el periodo de sometimiento a la tutela impuberum ${ }^{6}$, por razón de $\operatorname{edad}^{7}$, continuaban

2 S. DIXON, Infirmitas sexus: womanly weakness in Roman Law, en TI 52, 1984, p. 343, en donde afirma que la declaración de Cicerón hay que entenderla en el contexto de su estrategia de defensa como abogado: "As part of a general denunciation of lawyers' stratagems, Cicero cited the venerable example of tutela mulierum perpetua, whereby a Roman woman sui iuris (other than a Vestal) acquired for life a male tutor who monitored her economic activities. Cicero depicts the ancestral intention as being subsequently perverted by lawyers, who came up with a category of tutor subject to the woman rather than exercising authority over her", citando a continuación el fragmento que completa la oración contenida en el discurso a favor de Murena: hi invenerunt genera tutorum quae potestate mulierum continerentur.

3 CANTARELLA, E., La mujer romana, Santiago de Compostela, 1991, p. 10, en donde afirma que la mujer sui iuris es el principio y el fin de su familia, "en otras palabras, no tiene ningún poder sobre los hijos: una primera y no poco importante discriminación con respecto a las mujeres (por otra parte, sobreentendida en una organización patriarcal) a la que seguían muchas otras

4 D. 26. 1. 1. pr. (Paulus libro 38 ad edictum): Tutela est, ut servius definit, vis ac potestas in capite libero ad tuendum eum, qui propter aetatem sua sponte se defendere nequit, iure civili data ac permissa, en donde se ve claramente que la tutela no era un instrumento de fuerza y potestad tan sólo creado para el control de las mujeres, sino de toda persona libre, otorgado por el derecho civil para proteger a los sujetos que en razón de su edad o sexo no podían defenderse por sí mismos.

5 A. BERGER, Encyclopedic Dictionary of Roman Law, cit. s.v. tutela mulierum: "Guardianship over women sui iuris, i.e., who were neither that of her husband (manus). In the developed stage of the institution the principal function of the tutor mulieris was to give his authorization (auctoritas) to more important transactions or acts performed by the woman, such as manumission of slaves, acceptance of an inheritance, making a testament, assuming an obligation, alienations, constitution of a dowry, and the like. The women's weakness of sex, lightmindedness, and ignorance of business and courtaffairs are given as grounds for their protection through tutelage. The appointment of a woman' guardian was made in the same way as the tutela impuberum: by testament of the person in whose power (paternal or marital) she was, by law (tutela legitima of the agnates and of members of the gens, gentiles, in earlier times) or by a magistrate (tutela dativa).

6 Gayo 1. 189: Sed inpuberes quidem in tutela esse ómnium ciuitatium iure contingit, quia id naturali rationi coueniens est, ut is qui perfectae aetatis non sit, alterius tutela regatur... 
su existencia bajo una estricta vigilancia, quedando la capacidad de obrar femenina profundamente limitada, sometida al control y autoridad del tutor previsto ${ }^{8}$.

Esta institución se configuraba como un reflejo de la estructura familiar arcaica, puesto que no se presentaba como un mecanismo de protección, sino como la necesidad de controlar el patrimonio y los actos realizados por las mujeres, que quedaban así sometidas al hombre en una situación de incapacidad jurídica absoluta y perpetua ${ }^{9}$. Sin embargo, esta naturaleza supuestamente proteccionista de la tutela sobre la mujer, muy presente en los primeros años de esta institución, fue perdiendo poco a poco su significado y su razón de ser, hasta su total erradicación. Bien es cierto que el formalismo de la tutela se protegió durante mucho tiempo, y aunque en la práctica las mujeres llevaban a cabo todo tipo de actos y negocios jurídicos por sí mismas, necesitaban de la autoridad ${ }^{10}$, siquiera formal, de su tutor para poder completar la legalidad de determinadas acciones sometidas a control ${ }^{11}$.

En el estudio de esta clase de tutela sobre las mujeres, tutela mulierum, cabe destacar dos etapas claramente diferenciadas. Una primera etapa en la que la tutela se configuraba como una manifestación en la que se suplía, mediante esta nueva institución sobre las mujeres, la potestas del paterfamilias y la manus del marido. Su aparición estaba muy relacionada con la estructura primitiva y arcaica del grupo familiar, en el que todos los miembros de la familia

7 D. 27. 3.4 (Paulus libro 8 ad Sabinum): Nisi finita tutela sit, tutelae agi non potest: finitur autem non solum pubertate, sed etiam morte tutoris vel pupilli, en donde da cuenta que al llegar a la pubertad termina la tutela, pero también por la muerte de tutor o el pupilo; I. 1. 22. pr.: Pupilli pupillaeque cum puberes esse coeperint, tutela liberantur. pubertatem autem veteres quidem non solum ex annis, sed etiam ex habitu corporis in masculis aestimari volebant. nostra autem maiestas dignum esse castitate temporum nostrorum bene putavit, quod in feminis et antiquis impudicum esse visum est, id est inspectionem habitudinis corporis, hoc etiam in masculos extendere: et ideo sancta constitutione promulgata pubertatem in masculis post quartum decimum annum completum illico initium accipere disposuimus, antiquitatis normam in femininis personis bene positam suo ordine relinquentes, ut post duodecimum annum completum viripotentes esse credantur, en donde además de insistir en la tutela impuberum que termina para los puberes, refleja la edad establecida para cada sexo como medida de llegada a la pubertad: catorce años para los hombres, doce años para las mujeres.

8 Sabemos que no existió un único tipo de tutela, sin varios, cuya división según su origen ha sido objeto de debate por parte de la doctrina. Con todo, de forma habitual se tiende a clasificar los tipos de tutela en tres posibles (reflejados ya en la cita anterior de BERGER) la tutela testamentaria, la legítima y la dativa: La testamentaria, ordenada en el testamento por quien ejerce la patria potestad o la manus sobre la mujer; la legítima, a falta de tutor testamentario, que compete a los agnados, a los gentiles, o al manumisor y sus hijos; la dativa, posterior a las anteriores, que procede a falta de tutor testamentario o legítimo, conferida por el magistrado a instancia de la mujer, con la exigencia de que el tutor propuesto esté presente; vid. al respecto, L. SANZ MARTÍN, Estudio y comentario de las diferentes clases de tutela mulierum a tenor de lo referido en las fuentes jurídicas romanas. Funciones y responsabilidad del tutor mulierum, en Revista General de Derecho Romano 15, 2010, p. 4 ss.;

9 CANTARELlA, E., La calamidad ambigua, Madrid, 1991, p. 209, en donde da cuenta de la diferencia entre géneros en lo que se refiere a la capacidad de obrar en la época republicana: "En el derecho romano, en particular, los hombres se consideraban en grado de administrarse a sí mismos y sus propios intereses al alcanzar la edad púber. Por ello, aunque estuviesen libres de la patria potestas, estaban sometidos a tutela hasta que cumplían catorce años. Pero las mujeres - como establecieron las XII Tablas- estaban sometidas a tutela perpetua".

10 A. ERNOUT- A. MEILLET, Dictionnaire Etymologique de la Langue Latine, s.v. augere, raíz de nuestra palabra: "Faire croître, accroître; augmenter; amplifier", en el sentido de acrecer, reforzar, aumentar, amplificar, concretando en p. 57 ya con respecto a auctor: "en droit, auctor désigne le garant", trayendo a colación un texto de Cicerón, Caec. 72: "quod mulier sine tutore, auctore promiserit deberi".

11 J. IGLESIAS, Derecho Romano, $12^{a}$ ed., Barcelona 1999, p. 364, en donde destaca que en ningún caso actúa el tutor como negotiorum gestor, ya que la mujer administra ella misma su propio patrimonio, pero cuyo aval es imprescindible para la legalidad de determinados actos: "La función del tutor no es otra que la prestar su auctoritas -y siempre in presenti- a los siguientes actos celebrados por la mujer: 1. Enajenación de res mancipi. 2. In iure cesio. 3. Acceptilatio. 4. Aditio hereditatis. 5. Testamento. 6. Manumisiones. 7. Constitución de dote. 8. Asunción de toda clase de obligaciones. 9. Legis actio y iudicium legitimum. 10. Conventio in manum mediante coemptio. 11. Permiso a la liberta para quedar en contubernio con un esclavo ajeno". 
estaban bajo la potestas del paterfamilias ${ }^{12}$, titular del poder supremo sobre todos los miembros de la gens o grupo gentilicio, que ejercía una autoridad y potestad absoluta y sin ningún tipo de limitación, representado incluso en el ius vitae et necis, es decir, el derecho de vida y muerte que le convertía en juez supremo de la vida familiar. La tutela se configura como un mecanismo de protección de las expectativas hereditarias de los agnados sobre el patrimonio de la mujer ${ }^{13}$, que siendo sui iuris, es principio y fin de su propia familia ${ }^{14}$, para que no pueda perjudicar los intereses económicos del tronco agnaticio, convirtiéndose el agnado más próximo en su tutor a fin de preservar el patrimonio familiar ${ }^{15}$. Así se evita la dispersión de los bienes considerados propios de una determinada familia, a la par que se vigila la posible distracción de algunos efectos considerados imprescindibles por parte de las mujeres sui iuris que no estén sometidas a potestad alguna.

Una segunda etapa debemos situarla en la época clásica. En ella, la institución de la tutela mulierum ha ido evolucionando, al igual que la estructura y organización del grupo familiar. Con el paso del tiempo, la mujer fue ganando ciertas cotas de libertad e independencia entre otros motivos por las consecuencias de los innumerables conflictos bélicos en los que estaba inmersa la República. La desaparición de los padres, maridos y agnados de la vida de las mujeres provocó su presencia en múltiples actos jurídicos que antes hubieran sido inimaginables. Además, hizo su aparición el matrimonio sine manu, una nueva forma de unión matrimonial que consiste en la conservación por parte de la mujer del status previo a contraer matrimonio. Es decir, si en el matrimonio cum manu la mujer abandonaba a su familia de origen para pasar a formar parte de la familia de su marido, en esta nueva forma de matrimonio pueden suceder dos cosas diferentes: por un lado, que la mujer continúe bajo la patria potestad del pater como alieni iuris, por otro, que la mujer no quede sometida a la patria potestad de nadie, ni de su padre, ni de su marido, manteniendo la condición de sui iuris. En este último caso, la mujer sui iuris puede realizar negocios jurídicos e intervenir en los actos de disposición de su patrimonio, pero siempre con la autorización preceptiva de su tutor.

Esta distinción resulta importante a los efectos de conocer mejor a dos protagonistas de la historia de Roma: así, podremos entender la posición de Lucrecia, personaje femenino, entre el mito y la leyenda, que representa la máxima virtud de pureza y castidad que se citaba como ejemplo de la vida que debían llevar todas las matronas romanas. Su ubicación temporal, perteneciente al ámbito del derecho romano arcaico, sirve para explicar mejor su violento final, en el que defendió el honor de su familia por encima de su propia existencia tras ser violada por el hijo del último rey etrusco. Resulta evidente que, en un momento tan primitivo del derecho, aún no conformado siquiera con la Ley de las XII Tablas ${ }^{16}$, en la que ya se reconoce la exen-

12 J. A. CROOK, Law and Life of Rome, 90 B.C.- A. D. 212, Ítaca-Nueva York, 1967, p. 107, en donde dice que el principio agnaticio de la familia romana se perfecciona así: "Every member, male and female, was in the potestas of the oldest surviving male ascendant, the paterfamilias".

13 P. ZANNINI, Studi sulla tutela mulierum, II, Profili strutturalie vicende storiche dell 'istituto, Milán, 1979, p. 1-4; S. DIXON, Infirmitas sexus: womanly weakness in Roman Law, cit., p. 343: "Legal historians are generally agreed that the origin of tutela mulierum is to be explained in terms of the early Roman system of inheritance and was designed to safeguard male rights rather tan to protect women".

14 D. 50. 16. 195. 5 (Ulpianus libro 46 ad edictum): Mulier autem familiae suae et caput et finis est.

15 A. ARJAVA, Women and Law in Late Antiquity, Oxford- Nueva York 1966, p. 112: "As a daughter could inherit a considerable estate, it was in her brothers', uncles', and cousins' personal interest to see that she did not alienate property which would after her death revert to the family. That is why the nearest agnatic male relative automatically became the guardian (tutor legitimus), unless the father had appointed someone else in his will. This sistem was already eroded in the late republic, and Claudius finally abolished the agnatic guardianship".

${ }^{16}$ Gayo 1. 145: ... Loquimur autem exceptis uirginibus Vestalibus quas etiam ueteres in honorem sacerdotii liberas esse uoluerunt; itaque etiam lege XII tabularum cautum est; vid. contra la genuidad del texto gayano, S. SOLAZZI, Glosse a Gaio, en Studi Riccobono 1, Palermo 1936 p. 168 ss., de acuerdo con el uso impropio del término veteres, que podría haber sido utilizado aquí como los juristas anteriores a los decenviros; en desacuerdo, B. BIONDI, La 
ción de la tutela mulierum a las vírgenes vestales ${ }^{17}$, la dependencia de las mujeres con respecto a los hombres era total y absoluta, por lo que la tutela era un mecanismo connatural al hecho de ser mujer. Así, la tutela mulierum, es el reflejo de una estructura arcaica potestativa que se transforma en una situación de incapacidad jurídica absoluta y perpetua de la mujer ${ }^{18}$, lo que provoca que, con el paso del tiempo y el nacimiento de un nuevo tipo de sociedad en el mundo romano, esta institución quede vacía de contenido y poco a poco, la jurisprudencia y la propia sociedad romana la vean como una figura vacía, sin contenido.

Sin embargo, en el caso de Cornelia, la situación ha cambiado radicalmente: Independientemente de su riqueza, su condición de viuda ejemplar o su procedencia de una familia de noble origen quiritario, lo cierto y verdad es que Cornelia demuestra un grado de independencia en todos sus actos que hace presumir el escaso impacto real de la tutela en aquellos momentos, sobre todo para aquellas mujeres de su condición.

A mayor abundamiento, Cornelia pertenece a una familia de ilustre pasado como defensores de la Patria, inmersa continuamente en conflictos bélicos, sobre todo de carácter internacional, como resulta el protagonismo indiscutible de su padre en la segunda guerra púnica, y de su yerno en la destrucción de Cartago, lo que da cuenta de la ausencia prolongada de la autoridad masculina a la hora de relacionarse jurídicamente en el mundo romano.

Con todo, no podemos olvidar como la institución jurídica de la tutela seguía vigente, y seguirá siendo impuesta con carácter formal aún hasta la época imperial. Esta hipocresía jurídica resulta molesta, por cuanto la autoridad del tutor es necesaria para llevar a cabo determinados actos, reflejando todavía una incapacidad por cuestión de género que no es cierta, ni refleja la personalidad femenina, que cuando tiene acceso a la formación adecuada y a una educación adecuada, demuestra con sus actos que es tan capaz como un hombre, y en ocasiones mucho más, como demuestran la vida y actos de la propia Cornelia.

Así, en la época de Augusto empieza a agonizar la arcaica y demonizante tutela de las mujeres, con la legislación caducaria de Augusto ${ }^{19}$, en concreto por medio de la disposición

legislazione di Augusto, en Conferenze augustee nel bimillenario della nascita, Milán, 1939, p. 203, n. 2, en donde defiende la autenticidad del paso de Gayo, entendiendo que la norma relativa a las vestales fue recogida en la Ley de las XII Tablas.

${ }^{17}$ G. GIANNELLI, Il sacerdocio delle Vestali romane; Florencia, 1913; F. MÜNZER, Römische Adelsparteien und Adelsfamilien, Stuttgart, 1920; F. GUIZZI, Aspetti giuridizi del sacerdocio romano. Il sacerdocio di Vesta, Nápoles, 1968, passim; M. BEARD, The Sexual Status of Vestal Virgins, en JRS 70, 1980, pp.12 ss. donde destaca sobre todo la ambigüedad de las vestales; sobre la historia concreta de algunas de ellas, J. SCHEID, Claudia, la vestale. Roma al femminile, 1994, pp. 3-19. B. SCARDIGLI, Vestali integrate nella società romana, en Stud, hist., Ha. antig. 21, 2003, pp. 97-104; sobre la virginidad de las vestales, H. N. PARKER, Why Were the Vestals Virgins? Or the Chastity of Women and the Safety of the Roman State, en The American Journal of Philology, 125, 4, 2004, p. 568: "It is here that we can seek the symbolic function of the Vestal's virginity. Just as she embodied the city of Rome, so her unpenetrated body was a metaphor for the unpenetrated walls of Rome. This is manifest from the ancient sources. The powers of a Vestal were coterminous with the city walls".

${ }^{18}$ L. SANZ MARTÍN, Fundamentos doctrinales en torno a la tutela mulierum. Naturaleza y esencia de la tutela mulierum, en Revista General de Derecho Romano, 12, 2009, p. 5, añadiendo en p. 6: "La mujer romana sui iuris, cualquiera que fuese su edad, estaba siempre sometida al peso de la tutela: de impúber a la tutela impuberum, y de púber y para siempre a la tutela mulierum", trayendo a colación los textos de Gayo pertinentes al respecto, 1. 144: Permissum est itaque parentibus, liberis quos in potestate sua habent testamento tutores dare: masculini quidem sexus inpuberibus, <femini autem sexus cuiscumque aetatis sint et tum quo> que cum nuptae sint. Veteres enim voluerunt feminas, etiamsi perfectae aetatis sint, propter animi levitatem in tutela esse., y 1. 145: Itaque si quis filio filiaque testamento tutorem dederit, et ambo ad pubertatem pervenerint, filius quidem desinit habere tutorem, filia vero nihilo minus in tutela permanet...

19 J. EVANS GRUBBS, Women and the Law in the Roman Empire: A Sourcebook on Marriage, Divorce and widowhood, Londres-Nueva York, 2002, p. 24: "Augustus, as part of his promotion of marriage and procreation, granted women who served the state by child-bearing the ius (trium) liberorum". 
contenida en la lex Iulia de maritandis ordinibus (18 a.C.) y en la lex Papia Poppea ${ }^{20}$ (9 d.C.), que otorgaba el derecho, denominado ius trium liberorum ${ }^{21}$, de verse liberadas de la tutela obligatoria, a las mujeres que tuviesen tres o más hijos, si eran ingenuae, o cuatro si eran liber$\operatorname{tas}^{22}$. Aunque tal privilegio se concedía por vía de excepción, esta innovación jurídica transformaba la situación de las mujeres, convirtiéndolas en dueñas de sus propios actos y en pioneras de una libertad jurídica desconocida materialmente hasta ese momento.

A mayor abundamiento, el ius liberorum confiere a la mujer no sólo la liberación de la tutela bajo las condiciones que acabamos de ver, sino también la libertad de testar, la exención de la lex Voconia, por lo que una mujer podrá ser heredera de un cives romano cuya fortuna supere los cien mil ases y recibir todo el caudal testamentario sin reducciones como se hacía con los célibes, y sin disminuir la mitad de su legado, como se hacía con los huérfanos o los orbae que no tenían hijos. Además, tienen derechos especiales sobre la sucesión de los manumitidos $^{23}$, y en tiempos de Adriano, con el senatusconsultum Tertullianum ${ }^{24}$, tendrán derecho a la sucesión legítima de los hijos sui iuris muertos sin sucesión. Por último, el conocido ius $s_{\text {stola }} e^{25}$, o derecho a poder llevar la estola, prenda femenina que atestigua la condición de matrona de quién la lleva, otorga un prestigio social del que las mujeres romanas no están dispuestas a prescindir.

No será hasta tiempos del emperador Claudio ${ }^{26}$, cuando se entienda que la tutela agnaticia era un instrumento periclitado ${ }^{27}$, necesitado de refrendo legal para su derogación ${ }^{28}$, que

${ }^{20}$ Gayo 1. 145: ... Tantum enim ex lege Iulia et Papia Poppaea iure liberorum tutela liberantur feminae...; Ibid. id. 3. 44: Sed postea lex Papia cum quattuor liberorum iure libertinas tutela patronorum liberaret et eo modo concederet eis etiam sine tutoris auctoritate testamentum facere, prospexit, ut pro numero liberorum quos liberta mortis tempore habuerit, uirilis pars patrono debeatur...

21 A. BERGER, Encyclopedic Dictionary of Roman Law, cit., s.v. ius liberorum: "The most important application of ius liberorum concerned women. A freeborn woman with three children and a freedwoman with four children were freed from guardianship to which women were subject and had a right of succession to the inheritance of their children. The women's ius liberorum was applied even when the children were no longer alive"; C. 8. 59, 2, cuya denominación del título, De iure liberorum, explica la decisión de Justiniano: Illan iniuriam, quae contra matrem defuncti vel defunctae praeteritis fiebat temporibus, pro iustitiae ratione amputamus, et legitima iura, quae ex Tertulliano senatusconsulto ei praestantur, omnímodo eam haber sancimus, licet tres liberos ingenua, vel libertina quatuor minime pepererit; M. ZABLOCKA, Il "ius trium liberorum" nel diritto romano, en BIDR, 30, 1988, pp. 361-390.

22 Gayo 1. 194: Tutela autem liberantur ingenuae quidem trium <liberorum iure, libertinae uero quattuor, si in patroni>liberorumue eius legitima tutela sint; nam et ceterae quae alterius generis tutores habeant, uelut Atilianos aut fiduciarios, trium liberorum iure tutela liberantur.; Tit. ex corp. Ulp. 29. 3: Lex Papia Poppaea postea libertas quattuor liberorum iure tutela patronorum liberavit...; Tit. ex. corp. Ulp. 26. 8: sed si ius liberorum habeat, ingenua trium, libertina quattuor...; Paul. Sent. 4. 9. 1: Matres tam ingenuae, quam libertinae, cives Romanae, ut ius liberorum consecutae videantur, ter et quater peperisse sufficit, dummodo vivos et pleni temporis pariant; por último, Paul. Sent. 4. 9. 5: Septimo mense natus matri prodest, en el sentido de liberar a la madre, aunque el nacido fuera sietemesino y no un parto ordinario de nueve meses.

${ }^{23}$ Gayo 3. 51-52: 51. Quod autem ad libertinarum bona pertinet, siquidem intestatae decesserint, nihil noui patronae liberis honoratae lex Papia praestat. Itaque si neque ipsa patrona neque liberta capite deminuta sit, ex lege XII tabularum ad eam hereditas pertinet et excluduntur libertae liberi; quod iuris est etiam si liberis honorata non sit patrona; numquam enim, sicut supra diximus, feminae suum heredem habere possunt. Si uero uel huius uel illius capitis deminutio interueniat, rursus liberi libertae excludunt patronam, quia legitimo iure capitis deminutione perempto euenit, ut liberi libertae cognationis iure potiores habeantur. 52. Cum autem testamento facto moritur liberta, ea quidem patrona quae liberis honorata non est nihil iuris habet contra libertae testamentum; ei uero quae liberis honorata sit hoc ius tribuitur per legem Papiam, quod habet ex edicto patronus contra tabulas liberti.

${ }^{24}$ Inst. 3. 3. 2: Postea autem senatus consulto Tertulliano, quod divi Hadriani temporibus factum est, plenissime de tristi successione matri, non etiam aviae deferenda cautum est: ut mater ingenua trium liberorum ius habens, libertina quattuor ad bona filiorum filiarumve admittatur intestatorum mortuorum, licet in potestate parentis est, ut scilicet, cum alieno iuri subiecta est, iussu eius adeat, cuius iuri subiecta est.

${ }^{25}$ Fest. De verborum significatu, s.v. matronas: appellabant eas fere, quibus stolas habendi ius erat.

${ }^{26}$ G. MELILLO, La condizione femminile a Roma: Due norme di Claudio, en SDHI 68, 2002, p. 55 ss.

${ }^{27}$ G. MAY, L'activitè juridique de l'empereur Claude, en RHDFE 15, 1936, p. 235, en donde señala que la tutela legítima de los agnados era el lado débil de la tutela mulierum, ya que el tutor era desinado por razón de nacimiento, 
conocemos gracias al testimonio de Gayo, 1. 157, en el que además se insiste en la aparición de la misma en la época de las XII Tablas:

Sed olim quidem, quantum ad legem XII tabularum attinet, etiam feminae agnatos habebant tutores. Sed postea lex Claudia lata est ${ }^{29}$, quae quod ad feminas attinet <tales> tutelas sustulit; itaque masculus quidem inpubes fratrem puberem aut patruum habet tutorem, femina uero talem habere tutorem non potest.

Del mismo modo, contamos con una constitución del emperador León, en la que se recoge su derogación por parte del emperador Constantino ${ }^{30}$ :

C. 5. 30. 3: Constitutione divae memoriae constantini lege Claudia sublata, pro antiqui iuris auctoritate salvo manente agnationis iure tam consanguineus (id est frater) quam patruus ceterique legitimi ad pupillarum feminarum tutelam vocantur (a. 472).

A pesar de caer en el olvido, en el desuso y en la progresiva implantación de otros modos de resolver las lagunas de protección legal de las mujeres, como por ejemplo la figura del curator minoris recogida por Justiniano en sus Instituciones para las mujeres situadas en la franja de edad entre 14 y 25 años $^{31}$, la institución jurídica de la tutela no fue formalmente abo$\operatorname{lida}^{32}$, quizás porque formaba parte del origen ancestral del respetado ius civile ${ }^{33}$, pero las mujeres pasaron a tener una amplísima capacidad negocial, con un reforzamiento sustancial de su capacidad de obrar ${ }^{34}$.

\subsection{Infirmitas sexus}

La unión del calificativo de infirmitas con el vocablo sexus sí lo encontramos, por ejemplo, en un texto de Neracio $^{35}$, D. 27. 10. 9 (Ner. 1 membran.):

mientras que en los otros tipos de tutela, testamentaria o atiliana, el tutor se elegía de acuerdo con unos criterios de racionalidad.; vid. un estudio interesante sobre los diferentes tipos de tutela, G. BUIGUES OLIVER, La posición jurídica de la mujer en Roma. Presupuestos para un estudio de la capacidad negocial de la mujer, Madrid, 2014, p. 103 ss.

${ }^{28}$ M. J. CASADO CANDELAS, La tutela de la mujer en Roma, Valladolid, 1972, p. 117: "La tutela agnaticia de las mujeres, que representaba para el tutor sólo un radio de acción exactamente limitado a la auctoritatis interpositio, no podía sobrevivir largo tiempo, y el golpe de gracia estuvo a cargo de una disposición del emperador Claudio, en el año 44 d.C., la llamada ley Claudia.

${ }^{29}$ Gayo, 1. 171: Sed quantum ad agnatos pertinet, nihil hoc tempore de cessicia tutela quaeritur, cum agnatorum tutelae in feminis lege Claudia sublatae sint.

${ }^{30}$ Vid. del mismo emperador, C. 8.58 (Imp. Constantinus A (7) ad populum): Qui iure vetere coelibes habebantur, imminentibus legum terroribus liberentur... Quam rem et circa feminas aestimamus, earumque cervicibus imposita iuris imperia, velut quaedam iuga, solvimus promiscue omnibus.

${ }^{31}$ I. 1. 23. pr.: Masculi puberes et feminae viripotentes usque ad vicesimum quintum annum completum curatores accipiunt; qui licet puberes sint, adhuc tamen huius aetatis sunt, ut negotia sua tueri non possint.

32 J. F. GARDNER, Family and Familia in Roman Law and Life, Londres, 1998, p. 26, en donde señala que no se sabe cuánto tiempo duró la tutela, y que las referencias tardías no prueban que los cambios decididos por el pretor no hubieran tenido lugar; J. EVANS GRUBBS, Women and the Law in the Roman Empire: A Sourcebook on Marriage, Divorce and widowhood, cit., p. 24, en donde afirma que la tutela mulierum "has disappeared two centuries before Justinian", y por eso los compiladores de la magna obra de Justiniano omitieron cualquier referencia a la misma en el Digesto, el Código de Justiniano y sus Instituciones, así como en el Código de Justiniano, concluyendo que la única fuente para conocer la tutela de las mujeres en el periodo clásico la representa las Instituciones de Gayo.

${ }^{33}$ Cfr. O. TELLEGEN, Tutela mulierum, en Mulier. Algunas historias e Instituciones de Derecho Romano, R. RODRÍGUEZ LÓPEZ /M.J. BRAVO BOSCH (Eds.), Madrid, 2013, p. 417.

34 A. FERNÁNDEZ DE BUJÁN, Derecho Privado Romano, 9ª ed. Madrid, 2016, p. 196.

${ }^{35}$ The Oxford Classical Dictionary, N. G. L. HAMMOND/H. H. SCULLARD (eds.), Oxford, $2^{\text {a }}$ ed., 1971, s.v. Neratius: "Priscus, Lucius, a considerable Roman jurist of the age of Trajan and Hadrian; born at Saepinum in Samnium. He was praefectus aerarii Saturni, cos. suff. 97, legatus Augusti pro praetore of Pannonia, and he was at one 


\begin{abstract}
Cuius bonis distrahendis curatores facere senatus permisit, eius bona creditoribus vendere non permisit, eius bona creditoribus vendere non permisit, quamvis creditores post id beneficium bona vendere mallent; sicut enim integra re potestas ipsorum est, utrum velint, eligendi, ita quum alterum elegerint, altero abstinere debent. Multoque magis id servari aequum est, si etiam factus est curator, per quem bona distraherentur, quamvis nondum explicato eo negotio decesserit; nam et tunc ex integro alius curator faciendus est, neque heres prioris curatoris onerandus, quum accidere possit, ut negotio vel propter sexus, vel propter aetatis infirmitatem, vel propter dignitatem maiorem minoremve, quam im priore a curatore spectata erat, habilis non sit $^{36}$; possint etiam plures heredes ei existere, neque aut per omnes id negotium administrari expediat, aut quidquam dici possit, cur unus aliquis ex his potissimum onerandus sit.
\end{abstract}

En este fragmento, se alude a que el Senado no permitió a los acreedores la venta de los bienes de la persona para cuya enajenación de bienes estaba sometida a curadores, aunque después de este beneficio quisieran vender los bienes. Es un texto indirectamente relacionado con el léxico que estamos analizando, pero que viene a colación en el momento en el que se hace referencia a que no se debe gravar al heredero de un curador (en el texto se refiere al primero en el caso de que fallezca), ya que puede suceder que no sea apto para el negocio por motivos tales como la edad o la debilidad del sexo, siendo suficiente motivo para entender la incapacidad y la exoneración del gravamen.

Del mismo modo, encontramos la misma acepción en un texto de Paulo, contenido en D. 22. 6. 9 pr. (Paul. lib. sing. de iuris et facti ignorantia):

\begin{abstract}
Regula est iuris quidem ignorantiam cuique nocere, facti vero ignorantiam non nocere. Videamus igitur, in quibus speciebus locum habere possit, ante praemisso quod minoribus viginti quinque annis ius ignorare permissum est. Quod et in feminis in quibusdam causis propter sexus infirmitatem dicitur: et ideo sicubi non est delictum, sed iuris ignorantia, non laeduntur. Hac ratione si minor viginti quinque annis filio familias crediderit, subvenitur ei, ut non videatur filio familias credidisse.
\end{abstract}

Habida cuenta de la regla general de que la ignorancia del derecho perjudica igualmente, no así la ignorancia del hecho, vemos cómo Paulo concreta las excepciones existentes, la primera en relación con los menores de veinticinco años a los que se exime de perjuicio en caso de ignorancia del derecho, la segunda en referencia a las mujeres, cuya exención de posibles perjuicios se justifica por la debilidad de su sexo, propter sexus infirmitatem dicitur.

Cronológicamente hablando, debemos referirnos ahora a los textos de Marciano. El primero de ellos, D. 48. 16. 1. 10 (Marcianus libr. singulari ad senatus consultum Turpillianum):

\begin{abstract}
Accusationem is intulit, qui praescriptione summoveri poterat, ut quilibet adulterii masculo post quinque annos continuos ex die commissi adulterii vel feminae post sex menses utiles ex die divortii: an, si destiterit, hoc senatus consulto plecti debet, belle dubitatur. Movet, quod paene nulla erit accusatio, quam temporis spatium aut personae vitium omnimodo removeret reoque securitatem timoris ac periculi promitteret. Contra movet, quod qualiscumque accusatio illata cognoscentis auctoritate, non accusantis voluntate aboleri debet maioreque odio dignus existimaretur, qui temere ad tam improbam accusationem processisset. Ergo verius est eum quoque de quo loquimur in senatus consultum incidere oportere. Adquin Papinianus respondit
\end{abstract}

time, we are told, thought of by Trajan as his successor", añadiendo a continuación que Neracio fue con Celso, la última cabeza visible de la Escuela Proculeyana, además de ser miembro del consilium de Adriano y quizás Trajano. También se comenta la magnífica reputación de Neracio como jurista, demostrada por la cantidad ingente de citas realizadas por juristas posteriores, y además por el hecho de que Paulo escribiese un Comentario ad Neratium.

${ }^{36}$ T. MASIELLO, Modelli culturali e prassi giuridica fra gli Antonini e Severi, Nápoles, 1979, p. 30, en donde afirma que la incapacidad de la mujer para poder ser curator está relacionada con la idea de "un'infirmitas intesa in un significato naturalistico biologico". 
El lenguaje discriminatorio en la antigua roma y en la españa actual

mulierem, quae idcirco ad falsi accusationem non admitteretur, quod suam suorumve iniuriam non persequeretur, desistentem senatus consulto Turpilliano non plecti. Num ergo et in ceteris idem responsurus sit? Quid enim interest, propter sexus infirmitatem an propter status turpitudinem temporisve finem ad accusationem aliquam non admittatur? Multoque magis excludendi sunt, quod mulieris quidem accusatio vel propter proprium eius dolorem effectum habere potuit, illorum vero accusatio voce dumtaxat tenus intervenit. Adquin idem alias scribit non posse aliquem duos eodem tempore adulterii accusare, marem et feminam, et tamen, si utrique simul denuntiaverit, in utriusque persona abolitionem eum petere debere, ne in hoc senatus consulto incidat. Quid porro refert, propter causas supra scriptas accusatio non valuerit an propter numerum personarum non tenuerit? An haec intersint, plenam habuerit aliquis accusandi facultatem, sed propter personarum coniunctionem ab accusatione summoveatur, an vero stricta ratione quibusdam accusandi facultas non competat? Merito itaque dicendum est omnes excepta muliere et minore nisi abolitionem petierint, in hoc senatus consulto incidere.

Y en D. 49. 14. 18 pr. (Marcianus libr. singulari de delatoribus):

Deferre non possunt mulieres propter sexus infirmitatem, et ita sacris constitutionibus cautum est.

Un paso de Ulpiano contenido en D. 16. 1. 2. 2-3 (Ulpianus libro 29 ad edictum), resulta en principio el más polémico de todos ya que en vez de utilizar el calificativo ya conocido de infirmitas sexus, añade una nueva adjetivación del sexo femenino, sexus inbecillitatem:

2. Verba itaque senatus consulti excutiamus prius providentia amplissimi ordinis laudata, quia opem tulit mulieribus propter sexus inbecillitatem multis huiuscemodi casibus suppositis atque obiectis.

3. Sed ita demum eis subvenit, si non callide sint versatae: hoc enim divus Pius et Severus rescripserunt. Nam deceptis, non decipientibus opitulatur et est et Graecum Severi tale rescriptum: tais apatwsais gunaicin to dogma tys sugklytou boulys ou boyvei. [id est: decipientibus mulieribus senatus consultum non opilatur]. Infirmitas enim feminarum, non calliditas auxilium demeruit.

Este texto resulta en cierta medida muy contradictorio; por un lado, en virtud del Senadoconsulto Veleyano ${ }^{37}$, las mujeres quedan protegidas en caso de ser fiadoras de otras en asuntos de fianzas, o daciones en mutuo por otros, es decir, tomar dinero en préstamo para un terce$\mathrm{ro}^{38}$, ya que se les debe prestar auxilio en caso de ser engañadas. Pero el motivo del engaño no es la seducción por parte de otros o la malicia utilizada con determinadas argucias que las pudieran haber confundido y llevado a engaño, sino que su propia condición de mujeres es la que hizo que por "debilidad de su sexo" hubieran contraído tales obligaciones, y por ese motivo deben ser protegidas ${ }^{39}$. La acción positiva de la protección se anula con la causa de tal medida,

37 Vid. sobre el origen y fundamento del Senadoconsulto: H. VOGT, Studien zum Senatus Consultum Velleianum, Bonn, 1952; recensión de M. TALAMANCA en AG 143, 1942, pp. 172 ss.; D. MEDICUS, Zur Geschichte des Senatus Consultum Velleianum, Colonia-Graz, 1957; recensión de M. TALAMANCA, en Labeo, 4, 1958, pp. 99 ss.; A. D’ORS, Acerca de las acciones <ex SC velleiano〉, en Estudios Álvarez Suárez, Madrid, 1978, pp. 337 ss.; M. GARCÍA GARRIDO, El patrimonio de la mujer casada en el Derecho civil, Barcelona, 1982, pp. 123 ss.; R. ZIMMERMANN, The Law of Obligations. Roman foundations of the Civilian Tradition, Oxford-Nueva York, 1990, pp. 145 ss.; J. J. DE LOS MOZOS TOUYA, Los actos de intercesión y el Senadoconsulto Veleyano, en Derecho Romano de Obligaciones. Homenaje al profesor José Luis Murga Gener, Madrid, 1994, p. 463 ss., afirmando, con respecto a la fecha de emisión: "No fue anterior al Principado de Claudio, dado que Ulpiano alude a un edicto anterior, de Claudio, y, por otra parte, tampoco pudo ser posterior al año 65, en el cual fue desterrado Casio Longino por Nerón, pues Salvio Juliano cita un dictamen suyo sobre un problema de intercessio (D. 16. 1. 16. 1) que tiene que ser anterior a su destierro".

${ }^{38}$ D. 16. 1. 2. 4: Omnis omnino obligatio Senatusconsulto Velleiano comprehenditur, sive verbis, sive re, sive quocunque alio contractu intercesserint, en donde queda claro que en el Senadoconsulto Veleyano se comprende toda obligación, ya hubieran sido las mujeres fiadoras de palabra, de cosa, o mediante cualquier otro contrato.

39 R. QUADRATO, Infirmitas sexus e levitas animi: il sesso 'debole' nel linguaggio dei giuristi romani, en Scientia Iuris e Linguaggio nel sistema giuridico romano, F. SINI/R. ORTU (eds.), Milán, 2001, p. 159: "Nel pensiero dei 
la debilidad femenina como requisito para la concesión del auxilio previsto en el Senadoconsulto, confirmada por D. 16. 1. 2. 3, en donde se deja claro que la protección se concede si no hubieran procedido con malicia, en razón de un rescripto de Pío y Severo en el que se auxilia a las engañadas por su posición civil, las mujeres en general, pero no a las que engañan con malicia. Tal excepción no deja de sorprendernos, puesto que es el hecho de haber nacido mujer el origen de la incapacidad femenina a la hora de contraer obligaciones, por lo que deberíamos entender que esa discapacidad de las mujeres debería ser universal ante la realización de cualquier negocio. ¿Cómo dirimir la supuesta malicia, si ya por nacimiento las mujeres son incapaces? Tal minusvaloración biológica no debería hacer excepciones, y considerar a unas como posibles culpables ante las ventajas de los actos realizados, y a otras como susceptibles de protección ante las desventajas de las obligaciones contraídas.

Con todo, queda claro que es el hecho de ser mujeres y débiles el que constituye el objeto principal de protección por parte del Senadoconsulto Veleyano, que considera necesario ayudar a las mujeres solamente por su condición, imponiendo la necesidad de protegerlas y el rechazo a conceder reclamación contra ellas, como se recoge en D. 16. 1. 2 . 1 (Ulpianus libro 29 ad edictum $)^{40}$, ya que no es justo que ellas desempeñen oficios viriles, officia virilia ${ }^{41}$, y se liguen con obligaciones de este género:

Postea factum est senatus consultum, quo plenissime feminis omnibus subventum est. Cuius senatus consulti verba haec sunt: "Quod Marcus Silanus et Velleus Tutor consules verba fecerunt de obligationibus feminarum, quae pro aliis reae fierent ${ }^{42}$,

giuristi (dei più, ma non di tutti) anche il sesso -quello femminile, s'intende- è considerato causa di 'infermità': una condizione di invalidità, una menomazione che rende la donna, e quale che sia la sua età, incapace di assolvere a determinati compiti".

${ }^{40}$ El senadoconsulto Veleyano vino precedido de dos edictos de Augusto y Claudio, contenidos en D. 16. 1. 2. pr.: Et primo quidem temporibus divi Augusti, mox deinde Claudii edictis eorum erat interdictum, ne feminae pro viris suis intercederent, que ya prohibían la intercesión de las mujeres por sus maridos.

41 D. 3. 1. 1.5 (Ulpianus, libro 6 ad edictum): Secundo loco edictum proponitur in eos, qui pro aliis ne postulent: in quo edicto excepit praetor sexum et casum, item notavit personas in turpitudine notabiles. Sexum: dum feminas prohibet pro aliis postulare. Et ratio quidem prohibendi, ne contra pudicitiam sexui congruentem alienis causis se immisceant, ne virilibus officiis fungantur mulieres: origo vero introducta est a Carfania improbissima femina, quae inverecunde postulans et magistratum inquietans causam dedit edicto..., en donde se contiene la prohibición del Edicto del Pretor con respecto, entre otros colectivos, a las mujeres, por razón del sexo, añadiendo que el motivo de la prohibición viene dado por la propia condición femenina, para que las mujeres no se mezclen, contra la honestidad que les corresponde por cuestión de sexo, en causas ajenas ni desempeñen oficios propios de los hombres. Además, pone como ejemplo a Carfania, diciendo que fue una mujer corrompida, que abogó desvergonzadamente, tanto como para dar lugar al edicto; vid. sobre Carfania, E. HÖBENREICH, Andróginas y monstruos. Mujeres que hablan en la antigua Roma, en VELEIA, 22, 2005, p. 177: "Ulpiano coloca a las mujeres que no pueden postular a favor de terceros en el mismo plano que a ciertos incapaces. ¿Casualmente? Sobre la debilidad física y psíquica de las mujeres se ha escrito mucho; los juristas repiten el tópos a propósito de la necesidad de someter a las mujeres a la tutela mulierum. Es por tanto su naturaleza la que impone la prohibición, la que reclama un tratamiento especial. Quien viola una prohibición «natural», puede ser calificado de «desnaturalizado». La desviación de la naturaleza pide una amonestación, necesita que el ordenamiento jurídico proteja a todas las personas que se comportan conforme a su especie y que proteja a las «pervertidas» de sí mismas. Dejando al lado los esquemas de comportamiento transmitidos y recibidos de los antepasados que determinaron la exclusión de las mujeres de los oficios civiles y, más en general, de la participación en la vida pública, e ignorando el tono polémico y misógino de Ulpiano, que refleja un juicio masculino y moralizante al establecer el concepto de castidad adecuada para el otro sexo, constatamos una cosa muy significativa: Carfania debe haber sido una mujer habituada a presentarse ante la autoridad judicial presentando demandas, y parece haberlo hecho sin un apoyo o representante masculino. Eso supone conocimiento del derecho, así como experiencia forense. Ciertamente, Carfania no fue un caso aislado"; sobre officia virilia, C. PETROCELLI, La stola e il silenzio. Sulla condizione femminile nel mondo romano, Palermo, 1989, p. 289; R. RODRÍGUEZ LÓPEZ, La mujer en el mundo laboral de la Roma antigua, en Mulier. Algunas historias e Instituciones de Derecho Romano, R. RODRÍGUEZ LÓPEZ /M.J. BRAVO BOSCH (Eds.), Madrid, 2013, p. 245: "Las mujeres eran excluidas de toda labor civil y pública (officia virilia), no pudiendo ser jueces, ni ejercer magistraturas, aunque indirectamente participaban en la política y en las instituciones".

42 D. 3. 1. 1. 6, en donde se niega también la postulación ajena a quién con su cuerpo hizo de mujer: Removet autem a postulando pro aliis et eum, qui corpore suo muliebria passus est... 
quid de ea re fieri oportet, de ea re ita censuere: quod ad fideiussores et mutui dationes pro aliis, quibus intercesserint feminae, pertinet, tametsi ante videtur ita ius dictum esse, ne eo nomine ab his petitio neve in eas actio detur, cum eas virilibus officiis fungi et eius generis obligationibus obstringi non sit aequum, arbitrari senatum recte atque ordine facturos ad quos de ea re in iure aditum erit, si dederint operam, ut in ea re senatus voluntas servetur".

Bien es cierto que podríamos creer en la finalidad protectora de las disposiciones contenidas en el Senadoconsulto, como afirma parte de la doctrina romanística ${ }^{43}$, o insistir en el carácter limitativo de la posición jurídica de la mujer en Roma ${ }^{44}$, que es la posición que adoptamos. Es cierto que la intercessio femenina en asuntos de negocios, asumiendo obligaciones ajenas, era resuelta mediante la oposición a la demanda del acreedor en virtud del Senadoconsulto Veleyano, para evitar poner en peligro el patrimonio de la mujer. Pero la protección impuesta contenía claramente el prejuicio masculino con respecto a la capacidad negocial de la mujer, entendida como sexus inbecillitatem, presumiendo a priori la incapacidad de comprensión de los negocios jurídicos en los que se podía ver inmersa por su condición de fémina.

\subsection{Gayo: levitas animi.}

Mención aparte merece Gayo, ya que utiliza la expresión levitas animi en vez de infirmitas sexus en sus Instituciones ${ }^{45}$, una elección que no parece fruto de la casualidad ya que tiene un significado diferente, aunque ambas expresiones tengan una cierta afinidad. En la obra de Gayo no se utilizan jamás los términos latinos infirmitas, imbecilitas, fragilitas $^{46}$, utilizados con suma frecuencia por el resto de los juristas para describir la supuesta debilidad femenina. Sin embargo, Gayo, una figura ya singular de por sí en lo que respecta a su obra ${ }^{47}$, vuelve a

${ }^{43}$ M. GARCÍA GARRIDO, Ius Uxorium. El régimen patrimonial de la mujer casada en derecho romano, RomaMadrid, 1958, pp. 154 ss.; J. J. DE LOS MOZOS TOUYA, Los actos de intercesión y el Senadoconsulto Veleyano, cit. p. 465: "Un fin de exclusión y un fin protector parecen constituir así la ratio del precepto. Sin embargo, si se considera con más detenimiento la expresión de estas ideas, resulta, a mi juicio, claramente destacada, la finalidad de protección. En efecto, non sit aequum rige las dos oraciones subordinadas de infinitivo que expresan las dos ideas mencionadas, pero es indudable que su significado se refiere en primer lugar a eius generis obligationibus obstringi; y aunque gramaticalmente rige también a la frase anterior unida por un $e t$, no tiene mucho sentido respecto de eas virilibus officiis fungi. Esta última frase tendría pleno sentido si estuviera regida por un non decet o expresión similar. Con el modo de expresión efectivamente empleado ambas ideas aparecen concatenadas y se está queriendo decir que 'no es justo que las mujeres resulten vinculadas como consecuencia de la realización de negocios que pertenecen a la esfera de los hombres'. El SC expresa las dos ideas, de exclusividad viril de la intercessio y de protección de la mujer. Pero en primer plano está la protección".

44 P. GIDE, Étude sur la condition privée de la femme, $10^{\mathrm{a}}$ ed., París, 1885, p. 154, en donde afirma que la exclusión femenina de los officia virilia fue realizada por causa de la moral pública y en contra de las mujeres: "Le sénatusconsulte Velléien ne s'annonce point comme une innovation législative; il s'autorise d'une ancienne jurisprudence qu'il prétend maintenir et confirmer: Ita ius ante dictum esse videtur... L'exclusion de tout office viril fut établie contre les femmes et dans l'intérét de la morale publique. Si le sénatus-consulte n'est qu'une suite de cette exclusion, il faudra l'interpréter comme étant établi, non en faveur des femmes, mais contre elles"; F. SCHULZ, Principios de Derecho Romano, Madrid, 1990, pp. 229 ss. en donde afirma la reacción del Senado ante la emancipación de la mujer, con una disposición de marcado carácter limitativo.

45 J. C. LEDLIE, Gaius, en Journal of the Society of Comparative Legislation, 13, 2, 1913, p. 242, en donde da cuenta de la excelencia técnica de las Instituciones de Gayo: "It exhibits very clearly our author's two most salient characteristics, lucidity of expression and orderliness of arrangement. The style throughout is neat, vigorous, precise. The points are stated tersely and accurately. There is no rethoric, no redundancy. The points are stated tersely and accurately".

${ }^{46} \mathrm{~J}$. BEAUCAMP, Le vocabulaire de la faiblesse féminine dans les textes juridiques romains du III au IV siècle, en RHDEF 54, 1976, p. 487.

47 Vid. entre la numerosísima bibliografía al respecto: J. E. KUNTZE, Der Provinzialjurist Gajus, wissenschaftlich abgeschätzt, Leipzig, 1883; F. KNIEP, Der Rechtsgelehrte Gajus und die Ediktskommentare, Jena, 1910; P. KRÜGER, Geschichte der Quellen des römischen Rechts, 2ª ed., Leipzig, 1912, p. 204 ss.; F. WIEACKER, Zur 
distanciarse de sus coetáneos a la hora de describir a las mujeres, prefiriendo la utilización de levitas animi para expresar su especial condición.

Tal distinción a la hora de describir el estado femenino ha llevado a parte de la doctrina a reconocer en la obra gayana ecos de un cierto feminismo ${ }^{48}$, el deseo de superar la inferioridad secularmente atribuida a las mujeres utilizando para ello un lenguaje más igualitario para describir la condición femenina. Pero no nos llevemos a engaño, a pesar de la incertidumbre y misterio que rodea la figura del ilustre jurista ${ }^{49}$, a veces identificada como una mujer que ocultó su género para poder realizar su aportación jurídica sin mayores contratiempos ${ }^{50}$, no aprecia-

Geschichte des Gaiustextes, en Studi in onore di V. Arangio-Ruiz IV, Nápoles, 1953, pp. 193 ss.; M. KASER, Gaius und die Klassiker, en ZSSt, 70, 1953, pp. 127-178; A. M. HONORÉ, Gaius, Oxford, 1962; V. ARANGIO-RUIZ, Storia del diritto romano, Nápoles, 1966, en donde acusa a Gayo -en pp. 287 y 288- de ser un autor "privo di valore scientifico"; VV. AA., Gaio nel suo tempo. Atti del simposio romanistico, A. GUARINO, L. BOVE (eds.), Nápoles, 1966; R. MARTINI, Ricerche in tema di editto provinciale, Mailand, 1969; O. BEHRENDS, Die Prokuratur des klassischen röm. Zivilrechts, EN SZ 88, 1971, pp. 297 SS.; R. QUADRATO, Le Institutiones nell'insegnamento di Gaio: omissioni e rinvii, Nápoles, 1979; Donald KELLY, Gaius noster - Substructure of Western Social Thought, en The American Historical Review, 84, 3, 1979, pp. 609 ss.; A. M. GIOMARO, Spunti per una lettura critica di Gaio, Institutiones, Urbino, 1994, con serias dudas acerca de la existencia de Gayo en p. 11; J. M. BLANCH NOUGUÉS, Certissima iuris regula de Gayo, en RIDA 44, 1997, p. 45 ss.; G. FALCONE, Apunti sul IV comentario delle Istituzioni di Gaio, Turín, 2003; M. BRUTTI, Gaio e lo ius controversum, en AUPA 55, 2012, especialmente en pp. 96 ss.; F. BRIGUGLIO, Introduzione allo studio delle Istituzioni di Gaio, Biblioteca Gaiana, I, 2015 ; D. LIEBS, Römische Provinzialjurisprudenz, Friburgo, 2017, especialmente sus conclusiones a partir de la p. 60.

${ }^{48}$ R. QUADRATO, Infirmitas sexus e levitas animi: il sesso 'debole’ nel linguaggio dei giuristi romani, cit. p. 155 ss.

49 A. M. HONORÉ, Gaius, cit., p. 3 ss., en donde señala que el objetivo principal que pretende con su obra es aclarar los misterios que rodean la vida del gran jurisconsulto clásico que fue Gayo. Partiendo de la declaración de Pomponio (lib. 22 ad Quintum Mucium) contenida en D. 45. 3. 39, en la que reconoce a Gayo como 'Gaius noster', Honoré concluye que Gayo fue o el tutor de Pomponio o su colega de enseñanza: Cum servus, in quo usum fructum habemus, proprietatis domino ex re fructuarii vel ex operis eius nominatim stipuletur, adquiritur domino proprietatis: sed qua actione fructuarius reciperare possit a domino proprietatis, requirendum est. Item si servus bona fide nobis serviat et id, quod nobis adquirere poterit, nominatim domino suo stipulatus fuerit, ei adquirit: sed qua actione id reciperare possumus, quaeremus. Et non sine ratione est, quod Gaius noster dixit, condici id in utroque casu posse domino; sin embargo, D. PUGSLEY, Gaius or Sextus Pomponius, en RIDA 41, 1994, p. 362, afirma que debe tratarse de una interpolación la expresión Gaius noster, concluyendo en p. 363 que "Gaius and Pomponius were one and the same person", o más concretamente que Pomponio fue el autor no sólo de los trabajos que aparecen con su nombre sino también de los trabajos que aparecen con el nombre de Gayo; en contra de la teoría de Pugsley, vid. O. STANOJEVIC, Gaius and Pomponius. Notes on David Pugsley, en RIDA 44, 1997, comenzando por la p. 338: "I will try here to emphasize the weakness of PUGSLEY's hypothesis, to give some arguments proving that Gaius and Pomponius could not be the same person", realizando diversas objeciones: la primera con respecto al método utilizado por Pugsley, la segunda en relación con la producción científica, considerada imposible por no poder considerar a un autor tan prolífico como para poder llevar a cabo tal ingente número de obras, como refiere en p. 340: "If we apply those estimates the total number is from 440 to 490 volumes. It is a lot and probably impossible for one person to write. Even with books traditionally attributed to each one of them respectively (Gaius between 93 and 150, Pomponius between 320 and 350), those two are the most fertile authors of their time"; la tercera, aunque es cierto que Pomponio y Gato tenían mucho en común, es verdad que también se aprecian diferencias singulares, como revela en p. 341: "One of the striking differences is their destiny in legal history. Gaius is ignored by his contemporaries, except maybe, by Pomponius himself, and by lawyers of the two centuries that followed. Pomponius' work met immediate recognition. He was cited by such great names as Julian and he is one of the favorite authors of Ulpian, who cites his works on more than 300 occasions. Ulpian wrote his commentary on the ius civile by using as a model Pomponius' work Libri ad Sabinum. Later the situation has changed dramatically. The Lex citationis included Gaius in the restricted circle of five Paramount authorities. Pomponius appears nowhere, even among the jurists of the second rank, such as Scaevola, Sabinus, Julian and Marcellus", concluyendo que la diferencia de trato recibida por ambos, por parte de Justiniano y la anterior ley de Citas, demuestra las diferencias considerables con respecto a la naturaleza de su obra; además refiere la clasicidad de Pomponio y el mayor reconocimiento científico de éste, pero admite la innovadora clasificación de Gayo en sus Instituciones, que lo convierten de jurista modesto en un autor de elevado nivel científico, con un claro dominio de la lengua latina, refutando tanto la idea de "piratería intelectual" atribuida a Gayo como el hecho de ser la misma persona él y Pomponio.

${ }^{50}$ R. SAMTER, War Gaius das männliche pseudonym einer Frau?, en Deutsche Juristenzeitung, 13, 1908, pp. 13861391. 
mos en su legado jurídico un intento conciliador o innovador con respecto a las mujeres romanas.

Del análisis de los textos de Gayo en los que se contienen los términos levitas animi no podemos colegir un intento de mejorar la consideración del colectivo femenino en la antigua Roma, ni tampoco un significado más benevolente con la adjetivación del espíritu de la mujer en la antigua Roma. Aun poniendo en evidencia el significado en singular de levitas y animi, veremos cómo utilizados conjuntamente no otorgan una perspectiva innovadora con respecto al género femenino sino una forma diferente de visualizarlas, siempre desde una perspectiva discriminatoria de la que no se desprende el célebre jurista, al hablar de la ligereza de espíritu innata a las mujeres.

Veamos el primer texto de Gayo en el que se contienen las acepciones levitas animi, 1.144:

Permissum est itaque parentibus, liberis quos in potestate sua habent testamento tutores dare: masculini quidem sexus inpuberibus, <femini autem sexus cuiuscumque aetatis sint et tum quo> que cum nuptae sint. Veteres enim uoluerunt feminas, etiamsi perfectae aetatis sint, propter animi leuitatem in tutela esse.

Así, podemos ver como el jurisconsulto destaca como a los ascendientes se les permite que en su testamento nombren tutores para los descendientes que están bajo su potestad, concretando tal medida en los impúberes de sexo masculino y todos los de sexo femenino, aunque hayan contraído matrimonio. Justifica tal discriminación en el hecho de que ya los antiguos quisieron que las mujeres, aunque fueran adultas, estuvieran bajo tutela debido a su ligereza de espíritu. De este modo vemos como levitas animi se reconoce en un defecto común a todas las mujeres, su espíritu ligero, que parece más comprensivo que la expresión imbecillitas sexus, pero en realidad no es ningún avance espectacular con respecto a la nomenclatura de género. Como ha precisado ALBANESE ${ }^{51}$, el hecho de que Gayo rememore a los antiguos, veteres, $\mathrm{y}$ reclame la autoría de los mismos en lo que se refiere a la levitas animi, no lo convierte en ningún liberador de la injusta tutela femenina, sino todo lo contrario, ya que recurre a la respetada costumbre inveterada de los ancestros y a los mores maiorum, como fuente del derecho arcaico para seguir justificando la imposición de la tutela mulierum como mecanismo jurídico que vigile la innata debilidad femenina.

A mayor abundamiento, en otro texto gayano encontramos la identificación entre levitas e inconstantia, sencilla deducción obtenida de la contraposición que realiza el jurista entre el término negativo levis y el adjetivo en positivo constans, contenidos en D. 21. 1. 18 pr. (Gaius 1 ad ed. aed. Curul.):

\footnotetext{
Si quid venditor de mancipio adfirmaverit idque non ita esse emptor queratur, aut redhibitorio aut aestimatorio (id est quanti minoris) iudicio agere potest: verbi gratia si constantem aut laboriosum aut curracem vigilacem esse, aut ex frugalitate sua peculium adquirentem adfirmaverit, et is ex diverso levis protervus desidiosus somniculosus piger tardus comesor inveniatur. Haec omnia videntur eo pertinere, ne id quod adfirmaverit venditor amare ab eo exigatur, sed cum quodam temperamento, ut si forte constantem esse adfirmaverit, non exacta gravitas et constantia quasi a philosopho desideretur, et si laboriosum et vigilacem adfirmaverit esse, non continuus labor per dies noctesque ab eo exigatur, sed haec omnia ex bono et aequo modice desiderentur. Idem et in ceteris quae venditor adfirmaverit intellegemus.
}

${ }^{51}$ B. ALBANESE, Animi levitas femminile in Gai 1.144 e 190, en Annali del Dipartimento di Storia del Diritto della Università di Palermo, 48, 2003, p. 3: "Tanto più che, punto che mi pare discriminante, in Gai 1.144 il richiamo alla animi levitas muliebre è espressamente attribuito ai veteres (veteres enim voluerunt feminas...propter animi levitatem in tutela esse). Quindi, non è un rilievo che Gaio stesso sottolinea, come propria prospettiva, per staccarsi dalla concezione frequente di chi sottolineava l'infirmitas sexus". 
Este caso no se refiere en concreto a las mujeres, sino a la venta de un esclavo, y a las acciones que puede ejercitar el comprador en caso de no ser ciertas las características afirmadas por el vendedor con respecto al esclavo transmitido, acciones redhibitoria o estimatoria. Para establecer las excelentes cualidades de un esclavo en venta, se hace alusión a su constancia, laboriosidad, diligencia o frugalidad (relacionada con la compra del peculio gracias a su austeridad), en contraposición con las condiciones negativas de un esclavo ligero, desidioso, perezoso, pesado o dominado por la gula. La clara comparación entre el término constancia y ligereza da cuenta del significado que se le atribuye a la falta de constans, entendiendo levis como inconstancia, considerado grave como defecto en un esclavo, por lo que debemos colegir que en una mujer romana la atribución de una inconstancia permanente la degrada en su propia condición.

Gayo 1. 190:

Feminas uero perfectae aetatis in tutela esse fere nulla pretiosa ratio suassise uidetur; nam quae uulgo creditur, quia leuitate animi plerumque decipiuntur et aequum erat eas tutorum auctoritate regi ${ }^{52}$, magis speciosa uidetur quam uera ${ }^{53}$; mulieres enim quae perfectae aetatis sunt, ipsae sibi negotia tractant, et in quibusdam causis dicis gratia tutor interponit auctoritatem suam; saepe etiam inuitus auctor fieri a praetore cogitur.

En este paso gayano encontramos una cierta defensa del colectivo femenino en general, cuando Gayo afirma que apenas hay razón alguna de peso que persuada para que las mujeres adultas sigan bajo tutela, ya que lo que vulgarmente se cree, que son engañadas por la ligereza de su espíritu, motivo para someterlas a la autoridad de un tutor, es más una razón aparente que verdadera, magis speciosa uidetur quam uera. Las mujeres adultas llevan sus negocios, y hay casos en los que el tutor interpone su auctoritas por mero formalismo, e incluso con frecuencia debe autorizar actos contra su voluntad forzado por el pretor ${ }^{54}$.

Este texto es considerado por QUADRATO de una importancia extraordinaria ${ }^{55}$, ya que, en un alarde de audacia y modernidad, que ningún crítico puede quitarle al intelectual adrianeo, expresa su propia opinión con respecto a la innecesaria tutela femenina. Bien es cierto que la aseveración gayana se produce en una época del derecho clásico romano en el que las mujeres ya han conseguido ciertos avances, y en donde la arcaica tutela mulierum tiene poco recorrido, permaneciendo para el recuerdo sin derogar explícitamente, pero con una realidad más que ínfima en la sociedad romana. Pero aun así se agradecen las palabras del jurista en defensa de

52 J. J. DE LOS MOZOS TOUYA, Los actos de intercesión y el Senadoconsulto Veleyano, cit. p. 466: "Gayo rechaza en cambio el tópos de la levitas animi de las mujeres en relación con la tutela mulierum, afirmando la razón originaria del interés de los herederos, concluyendo que el problema con respecto a la intercessio no es de ligereza del carácter de las mujeres, "sino de situación de inferioridad para determinadas actuaciones como consecuencia de su posición en el mundo civil".

53 C. FAYER, La familia romana, Roma, 1994, p. 528: "Solo nella seconda metà del II sec. d.C., il giurista Gaio critica apertamente la motivazione correntemente addotta per giustificare la tutela sulle donne puberi e ne riconosce la speciosità. Egli, infatti, riconosce che nulla pretiosa ratio giustificava la tutela mulierum e non riesce a convincersi che una donna maggiorenne, che da sè amministrava ormai i suoi affari, dovesse essere sottoposta a tutela".

${ }^{54}$ Motivo por el cual, se añade en el siguiente comentario, Gayo 1. 191, que las mujeres no pueden seguir un juicio contra el tutor, mientras que los pupilos sí pueden entablar contra sus tutores un juicio de tutela, una vez que han llegado a la pubertad: Vnde cum tutore nullum ex tutela iudicium mulieri datur; at ubi pupillorum pupillarumue negotia tutores tractant, eis post pubertatem tutelae iudicio rationem reddunt.

55 R. QUADRATO, Infirmitas sexus e levitas animi: il sesso 'debole’ nel linguaggio dei giuristi romani, cit. p. 177, donde destaca la intención perseguida por Gayo: "mostrare l'inconsistenza della posizione che discriminava la donna, denunciare il carattere chiaramente pretestuoso di una normativa che si appellava alla particolare natura del sesso per motivarne l'inferiorità física e intellettuale e la conseguente incapacità", todo ello acompañado de un relato con sentimiento y vehemencia para suscitar emociones, en donde Gayo expresa sus propias convicciones para persuadir a sus interlocutores. 
un colectivo casi siempre en el punto de vista negativo del ius romanorum. ALBANESE ${ }^{56}$, por otro lado, no pone en duda que ciertamente el documento de Gayo demuestra una inteligente reacción del jurista con respecto a los remotos andamiajes culturales que estaban subyacentes a las reglas del ius civile sobre la tutela muliebre. Pero la crítica de la tesis viene dada en lo que se refiere a la valoración del término levitas, para nada demostrativo de una consideración positiva con respecto a la mujer.

Así, QUADRATO opta por alabar la sensibilidad de Gayo a la hora de dirigirse a las mujeres, con la expresión -jamás utilizada anteriormente- levitas animi, realizando una elección léxica única a la hora de referirse al colectivo femenino, y subrayando la presencia del término levitas como algo esencial, diferente, que introduce algo nuevo en su discurso, desviándose de la línea tradicional para atraer la mirada del lector, que podrá comprobar como la justificación de la debilidad femenina es inconsistente ${ }^{57}$. Sin embargo, ALBANESE niega la acepción benévola de levitas, afirmando que levis y levitas son términos utilizados en una época anterior a la de Gayo, y además, "sarebbero stati usati con connotazione fortemente negativa" ${ }^{98}$. Además, añade, si tomamos como ejemplo un pasaje de Aulo Gelio, Noctes Atticae 6. 11. 1, podemos observar la sinonimia negativa que se establece entre levitas y la inconstancia o la mutabilidad, en otras palabras, la debilidad de espíritu ya mencionada:

\footnotetext{
Neque "levitatem" neque "nequitiam" ea significatione esse, qua in vulgi sermonibus dicuntur. "Levitatem" plerumque nunc pro inconstantia et mutabilitate dici audio et "nequitiam" pro sollertia astutiaque ${ }^{59}$.
}

Nosotros creemos que la actitud del jurista Gayo no resulta tan proclive al género femenino como se pudiera pensar. No podemos colegir del empleo de los términos levitas animi una encendida defensa en pro de los derechos de las mujeres, en innegable situación de inferioridad, como se aprecia en un conocido texto de Papiniano recogido en D. 1. 5. 9 (Papinianus libro 31 quaestionum):

${ }^{56}$ B. ALBANESE, Animi levitas femminile in Gai 1.144 e 190, cit. p. 2, en donde añade: "E infine non vi è dubbio che la presa di posizione di Gaio costituisca una prova dell'apertura mentale e della capacità critica di quel giurista, che, ancor oggi, secondo noi a torto, molti continuano a considerare spesso come scrittore mediocre, poco rigoroso, poco chiaro, se non addirittura irrilevante".

${ }^{57}$ R. QUADRATO, Infirmitas sexus e levitas animi: il sesso 'debole’ nel linguaggio dei giuristi romani, cit. p. 187: "In confronto all'infirmitas sexus, che è la ratio antica, ricorrente -un argomento forte, perchè implica un rapporto gerarchico tra i sessi- la levitas animi è una giustificazione debole, una ingenuità, un moptivo quasi banale, inidóneo perciò a motivare la diversità di trattamento tra maschi e femmine. È qui il punto critico, l'elemento cruciale (e decisivo) di tutta l'operazione gaiana: nell'abbandono di un linguaggio discriminatorio che incarnava e ricalcava schemi vecchi, prefabbricati, e nell'adozione di parole che tenessero conto della realtà, della 'quotidiana sperienza' della donna; la quale non è, per natura, più debole dell'uomo, e non è perciò incapace di operare, di negoziare", añadiendo a continuación que para seleccionar la palabra justa, Gayo optó por la lengua común.

58 B. ALBANESE, Animi levitas femminile in Gai 1.144 e 190, cit. p. 2, en donde reclama nuestra atención en un texto de Cicerón, Phil. 2. 31. 77, che incide sobre la levitas di Marco Antonio: At videte levitatem hominis. Cum hora diei decima fere ad Saxa rubra venisset, delituit in quadam cauponula atque ibi se occultans perpotavit ad vesperam; inde cisio celeriter ad urbem advectus domum venit capite obvoluto. Ianitor: 'Quis tu?' 'A Marco tabellarius. ' Confestim ad eam, cuius causa venerat, [deducitur] eique epistulam tradidit. Quam cum illa legeret flens (erat enim scripta amatorie; caput autem litterarum sibi cum illa mima posthac nihil futurum; omnem se amorem abiecisse illim atque in hanc transfudisse), cum mulier fleret uberius, homo misericors ferre non potuit, caput aperuit, in collum invasit. O hominem nequam! Quid enim aliud dicam? magis proprie nihil possum dicere. Ergo, ut te Catamitum, nec opinato cum te ostendisses, praeter spem mulier adspiceret, idcirco urbem terrore nocturno, Italiam multorum dierum metu perturbasti?. El autor nos dice sobre el pasaje en cuestión: "Cicerone accusa Antonio proprio di levitas adducendo un episodio specifico. Il triumviro, per via di una tresca con una mima, s'era camuffato da fattorino; aveva trascorso ore in un'osteria; si era ubriacato; aveva consegnato, fingendosi semplice latore, all'attrice una lettera per troncare il rapporto con lei; e però aveva subito scoperto il volto appena la donna si era messa a piangere. Tuttavia, a me sembra che levitas per Cicerone, qui come in altri passi, significhi fondamentalmente "leggerezza, incostanza". La levitas di Antonio, per Cicerone, non consisteva però tanto nel ridicolo contegno del travestimento, 59 bensì nell'aver mutato avviso alle prime lacrime femminili". 
In multis iuris nostri articulis deterior est condicio feminarum quam masculorum.

Su posición debería hacer sido de profundo rechazo y no de ambigüedad, aludiendo a que apenas había razón alguna de peso para que las mujeres adultas sigan bajo tutela. Si él creía fervientemente en la igualdad de $\operatorname{sexos}^{60}$, debería haberlo demostrado en su discurso con la misma claridad que definía muchos otros conceptos en sus Instituciones, y no utilizar medias palabras por el temor a que no fueran bien recibidas. Como dice ALBANESE ${ }^{61}$, Gayo podría haber añadido el hecho de que una ley Claudia, recordada por él mismo en 1. 157, ya había suprimido la tutela agnaticia sobre las mujeres sui iuris con la excepción del patrono sobre la liberta, en realidad no agnaticia.

\section{LENGUAJE Y GÉNERO EN LA ESPAÑA ACTUAL}

Resulta evidente que un salto temporal tan grande no puede ponerse en comparación de una forma razonable en lo que se refiere a los derechos de la mujer y el lenguaje utilizado para referirse a la condición femenina. Hoy en día el escenario es totalmente distinto en España, que no en el resto del mundo, pero hemos tenido que realizar un largo camino para poder llegar a los términos de igualdad de los que hoy gozamos en el lenguaje cotidiano.

Esta lucha en favor de la paridad fue larga y tortuosa, pudiendo nombrar en primer lugar a Concepción Arenal como la pionera del feminismo en nuestro país, y en particular por la puesta en evidencia de la inferioridad de la mujer ${ }^{62}$, ya en el siglo XIX, realizando un magnífico trabajo en pro de los derechos de las mujeres, al margen de su destacada y conocida lucha por la mejora de la situación en las cárceles de mujeres y hombres

En la misma dirección, es necesario referirse a una de las grandes figuras de la historia del siglo XX en nuestro país, Clara Campoamor. Fue una abogada, política y gran luchadora por los derechos de todas las mujeres ${ }^{63}$, en un marco histórico donde éstos eran mínimos. Campoamor aprovechó la modificación de la ley electoral que llegó de la mano de la II República Española, que permitía a las mujeres mayores de veintitrés años poder ser elegidas en el

${ }^{60}$ R. QUADRATO, Infirmitas sexus e levitas animi: il sesso 'debole’ nel linguaggio dei giuristi romani, cit. p. 193: "Per Gaio, insomma, non c'è differenza tra maschio e femmina; non c'è disuguaglianza fra i sessi. Circola in questa visione l'idea di una parità, non solo biológica, ma anche intellettuale, tra uomo e donna", concluyendo que la simpatía de Gayo por las mujeres (al margen de que no suponga ningún indicio de la condición femenina de Gayo, es decir, de la posibilidad de que el jurista hubiera sido una mujer) no es feminismo, sino lucha contra la discriminación.

${ }^{61}$ B. ALBANESE, Animi levitas femminile in Gai 1.144 e 190, cit. p. 3: "Gaio avrebbe potuto aggiungere, a conferma della già maturata convinzione della radicale irrazionalità della tutela sulle donne puberi, il fatto che una lex Claudia, che egli stesso aveva ricordato poco prima (Gai 1.157; cfr. 1.171; ma v.a. Tit.Ulp. 11.8; CTh.3.17.2 e C.5.30.30), aveva, già da tempo, certo, soppresso la tutela agnatizia sulle donne sui iuris con eccezione di quella del patrono sulla liberta, in realtà non agnatizia ma assimilata alla tutela agnatizia".

62 C. ARENAL, La mujer del porvenir, Madrid, 1869, reimp. Alicante, Biblioteca Virtual Miguel de Cervantes, 2010, p. 12, en donde muestra las contradicciones en cuanto a la capacidad de la mujer: "Si la ley civil mira a la mujer como un ser inferior al hombre, moral e intelectualmente considerada, ¿por qué la ley criminal la impone iguales penas cuando delinque? ¿Por qué para el derecho es mirada como inferior al hombre, y ante el deber se la tiene por igual a él? ¿Por qué no se la mira como al niño que obra sin discernimiento, o cuando menos como al menor? Porque la conciencia alza su voz poderosa y se subleva ante la idea de que el sexo sea un motivo de impunidad: porque el absurdo de la inferioridad moral de la mujer toma aquí tales proporciones que le ven todos: porque el error llega a uno de esos casos en que necesariamente tiene que limitarse a sí mismo, que transigir con la verdad y optar por la contradicción. Es monstruosa la que resulta entre la ley civil y la ley criminal; la una nos dice: -Eres un ser imperfecto; no puedo concederte derechos. - La otra: - Te considero igual al hombre y te impongo los mismos deberes; si faltas a ellos incurrirás en idéntica pena."

${ }^{63}$ C. CAMPOAMOR, El voto femenino y yo: Mi pecado mortal, Ed. Horas y Horas, Madrid, 2006, passim. 
Parlamento, logrando obtener su escaño en el poder ${ }^{64}$. Una vez allí, tomó la palabra en el Congreso de los Diputados para reclamar un derecho político básico, el voto, por lo que siempre será recordada como la impulsora del sufragio femenino en España, y por solicitar la eliminación de cualquier sesgo de discriminación en contra de las mujeres en la nueva constitución republicana ${ }^{65}$.

A pesar del gran esfuerzo realizado por ellas, la verdad es que tuvo que pasar mucho tiempo hasta llegar a la promulgación de la Ley Orgánica 3/2007, de 22 de marzo, para la igualdad efectiva de mujeres y hombres, cuyo artículo 14. 11, deja clara la necesidad de un nuevo lenguaje que ayude a la necesaria paridad: "La implantación de un lenguaje no sexista en el ámbito administrativo y su fomento en la totalidad de las relaciones sociales, culturales y artísticas". Del mismo modo, en la citada ley, artículo 24: Integración del principio de igualdad en la política de educación, recoge en el apartado 2. b, un principio esencial para evitar la discriminación femenina, como es la supresión del lenguaje sexista en los contenidos dirigidos a la educación: "La eliminación y el rechazo de los comportamientos y contenidos sexistas y estereotipos que supongan discriminación entre mujeres y hombres, con especial consideración a ello en los libros de texto y materiales educativos".

Con todo, y al margen de la necesidad de adaptar los libros de texto al lenguaje correcto en pro de la igualdad queda manifiestamente clara, creemos que la implantación de un lenguaje no sexista en el ámbito administrativo se debe hacer con un asesoramiento multidisciplinar. Abogar por los lenguajes inclusivos en ausencia de lingüistas no parece lo más adecuado si éstos son los protagonistas del correcto uso del lenguaje en nuestro territorio ${ }^{66}$.

${ }^{64}$ F. ÁLVAREZ-URÍA, Mujeres y política. Las políticas de las mujeres en la España de la Segunda República y la Guerra Civil, en Papers, 2013, 98/4, p. 633, en donde da cuenta no sólo de la figura de Clara Campoamor, sino de todas las mujeres protagonistas del cambio radicalmente positivo que supuso el derecho al voto femenino : "Fue durante la Segunda República y la Guerra Civil, es decir, en un lapso de tiempo de ocho años, entre 1931 y 1939 , cuando las mujeres españolas entraron por vez primera en las Cortes de la Carrera de San Jerónimo, cuando conquistaron el derecho al voto, cuando militaron activamente en los partidos políticos y pugnaron por salir elegidas diputadas en las contiendas electorales. En el análisis que sigue, se parte de los textos autobiográficos de cinco mujeres. Dos representan al llamado feminismo burgués: Clara Campoamor y Victoria Kent, que nacieron, respectivamente, en 1888 y 1898. Las otras tres representan al llamado feminismo revolucionario: Dolores Ibárruri, Irene Falcón y Federica Montseny, que nacieron en 1895, 1907 y 1905, respectivamente".

${ }^{65}$ NASH, M., "Género y ciudadanía", Ayer, 20, 1995, p. 249: "Defensora acérrima de una ciudadanía política no restringida por el sexo, encabezó la defensa del sufragio femenino en las Cortes Constituyentes y asumió una clara postura de signo igualitario, argumentando que los derechos del individuo exigían un igual tratamiento legal de hombres y mujeres. Para la diputada radical los principios democráticos debían garantizar la aplicación de la igualdad y la eliminación de cualquier discriminación de sexo en la Constitución republicana".

${ }^{66}$ I. BOSQUE, Sexismo lingüístico y visibilidad de la mujer, en Información lingüística de la RAE, ponente de la nueva gramática de la lengua española, p.1: "En los últimos años se han publicado en España numerosas guías de lenguaje no sexista. Han sido editadas por universidades, comunidades autónomas, sindicatos, ayuntamientos y otras instituciones... La mayor parte de estas guías han sido escritas sin la participación de los lingüistas. Cabe pensar que los responsables o los impulsores de las demás guías entienden que no corresponde a los lingüistas determinar si los usos verbales de los hispanohablantes son o no sexistas. Aunque se analizan en ellas no pocos aspectos del léxico, la morfología o la sintaxis, sus autores parecen entender que las decisiones sobre todas estas cuestiones deben tomarse sin la intervención de los profesionales del lenguaje, de forma que el criterio para decidir si existe o no sexismo lingüístico será la conciencia social de las mujeres o, simplemente, de los ciudadanos contrarios a la discriminación" en p. 2: "Entre los aspectos que comparten las guías de lenguaje no sexista destaca sobre todo una argumentación implícita que me parece demasiado obvia para ser inconsciente. Consiste en extraer una conclusión incorrecta de varias premisas verdaderas, y dar a entender a continuación que quien niegue la conclusión estará negando también las premisas. La primera premisa verdadera es el hecho cierto de que existe la discriminación hacia la mujer en nuestra sociedad."; en p. 3. "La segunda premisa, igualmente correcta, es la existencia de comportamientos verbales sexistas... La tercera premisa verdadera es el hecho de que numerosas instituciones autonómicas, nacionales e internacionales han abogado por el uso de un lenguaje no sexista", añadiendo en p. 4: "De estas premisas correctas, en cierta forma subsumidas en la última, se deduce una y otra vez en estas guías una conclusión injustificada que muchos hispanohablantes consideramos insostenible. Consiste en suponer que el léxico, la morfología y la sintaxis de 
En el artículo 28 de la ley, se insiste, con respecto a la Sociedad de Información, en la necesidad de proyectos que apuesten por la igualdad, en su apartado 4: "En los proyectos del ámbito de las tecnologías de la información y la comunicación sufragados total o parcialmente con dinero público, se garantizará que su lenguaje y contenidos sean no sexistas".

Y con respecto a la Corporación RTVE, en el artículo 37. 1. b., y la Agencia Efe, artículo 38. 1. b., se les pide, para transmitir una imagen igualitaria, plural y no estereotipada de las mujeres en la sociedad: "Utilizar el lenguaje en forma no sexista".

La necesidad de una legislación de este tipo existe cuando se percibe en la sociedad un comportamiento discriminatorio con respecto a las mujeres, lo que da cuenta del camino que aún debemos recorrer en materia de igualdad. Fue un proyecto novedoso en su momento, una iniciativa magnífica y llena de buenas intenciones, pero la realidad es que la aplicación práctica en muchas ocasiones ha sufrido los envites de la ambigüedad, cuando no las críticas por la preferencia femenina en determinadas ayudas y subvenciones que han quedado luego al descubierto por ciertas prácticas engañosas.

Con todo, aplaudimos iniciativas de este tipo, pero que no se queden en meros protocolos formales de lenguaje en contra del patriarcado, o prácticas machistas aún existentes. El lenguaje inclusivo es un medio, pero debe ser coherente con las normas de la Real Academia Española, coherente con la sociedad que vivimos, y coherente con la posición equivalente de igualdad que predica la mujer, para conseguir el objetivo final, que no es otro que la ansiada paridad que exigimos como connatural al nacimiento, y que conduzca a la desaparición definitiva de la discriminación por razón de género.

Recebido em: 3 jan. 2018.

Aceito em: 10 jun. 2018.

nuestra lengua han de hacer explícita sistemáticamente la relación entre género y sexo, de forma que serán automáticamente sexistas las manifestaciones verbales que no sigan tal directriz, ya que no garantizarían "la visibilidad de la mujer". 